\title{
De la sociedad civil a la sociedad política: otra ciudadanía es posible.
}

\author{
From the civil society to the political society: \\ Another possible citizenship.
}

Por: Puyol, Juan Jesús*

UNNE

Resistencia, Argentina.

Email: juanjpuyol@gmail.com

Fecha de recepción: 03/07/2020

Fecha de aprobación: 31/07/2020

DOI: $\underline{\text { http://dx.doi.org/10.30972/nvt.1624492 }}$

\section{Resumen}

En este trabajo me propongo analizar cómo la discusión de Hegel de nociones En los últimos años, se ha constatado que la cuestión referida a los procesos de formación y agencia de la ciudadanía ha logrado ocupar un lugar relevante en el interés investigativo de diversos campos disciplinares. Se percibe la actualidad de un horizonte teórico de permanente debate acerca de cómo se emplaza la noción de

\footnotetext{
* Este trabajo contribuye a los desarrollos y avances del Proyecto de Investigación denominado "Cuerpo viral/virtual: la (auto)contaminación. Reflexiones filosóficas marginales. Repensando el tópico desigualdad". 18H010/18. Resolución N 1100/18 -C.S. Período: 2019-2022. Universidad Nacional del Nordeste.

* Profesor y Licenciado en Filosofía por la Universidad Nacional del Nordeste (UNNE). Auxiliar Docente de Primera Interino en la cátedra Metodología de las Ciencias Sociales. Facultad de Ciencias Económicas de la UNNE. Diplomado Universitario en Filosofía de la Liberación por la Asociación de Filosofía y Liberación y Facultad de Humanidades y Ciencias Sociales de la Universidad Nacional de Jujuy. Alumno Regular del Doctorado en Filosofía. Facultad de Humanidades de la UNNE. Sus principales tópicos de investigación refieren a la Ética y a la Filosofía Política desde la filosofía latinoamericana, la Filosofía de la Liberación y el pensamiento post/descolonial. Tales avances logrados han sido publicados en diversas revistas académicas, Jornadas de Investigación, Congresos y Reuniones Científicas. A su vez, ciertos resultados obtenidos mediante Becas de Investigación han sido objeto de distinciones otorgadas por la UNNE. En la actualidad, su proyecto doctoral se centra en la vinculación categorial alteridadtransmodernidad del pensamiento de Enrique Dussel como un posible aporte descolonial a las problemáticas de la inclusión. La Dirección de dicha instancia académica se encuentra a cargo del Dr. Alejandro Auat y la Co-dirección a cargo de la Dra. María Mercedes Oraisón.
} 
De la sociedad civil a la sociedad política: otra ciudadanía es posible.

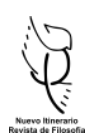

ciudadano, cuáles son sus límites discursivos de representatividad y qué expectativas le cabe aún como concepto clave de lo político, en tanto se enuncia como una de las máximas herencias provocadas por la modernidad.

Desde el terreno discursivo habilitado por los intercambios entre el pensamiento post/decolonial y la Filosofía de la Liberación, este trabajo presenta una posible indagación crítica de la categoría ciudadanía a partir del abordaje analítico de dos planos de relevancia investigativa. Por un lado, el tipo de incidencia epistémica que provoca dicho término en el contexto de una modernidad colonial vigente; por otro, la dimensión interpelante desde la cual podría operar esta categoría en el campo político. Interrogar los condicionamientos ético-epistémicos que definen en el presente a la noción mencionada será uno de los ejes transversales a las reflexiones que se expondrán. Tal estrategia constituirá el desafío de advertir nuevas vías de análisis filosófico a partir de las cuales el concepto ciudadanía pueda ser re-apropiado desde una dimensión crítica-liberadora.

Palabras clave: colonialidad, alteridad, principios democráticos, gobierno, solidaridad.

\footnotetext{
Abstract

In the last years, it has been verified that the question referred to the processes of formation and the citizenship agency have reached a relevant place in the investigation interests from different disciplinary fields. It is perceived today of a theoretical horizon of constant debate about how the notion of citizenship is situated, which are its discursive limits of representativity what expectations can be taken as a key concept of politics, meanwhile it is announced as one of the maximum inheritances provoked by modernity.

From the discursive field enabled by the exchanges between the post/decolonial thought and the Philosophy of Liberality, this work presents a possible critical inquiry of the citizenship category from an analytical approach of two plans of investigative relevance.
} 
On the one hand, the type of epistemic incidence that provokes that concept in the context of a current colonial modernity; on the other hand, the questioning dimension from which this category could operate in the political field. Questioning the ethicepistemic conditionings that define nowadays the mentioned notion will be one of transversal axis to the reflections to be exposed. That strategy will constitute the challenge to notice new ways of philosophical analysis from which the concept of citizenship could be re-appropiate from a critical- liberating dimension.

Keywords: coloniality, otherness, democratic principles, government, solidarity.

\section{Cómo citar este artículo:}

APA: Puyol, J. J. (2020) De la sociedad civil a la sociedad política: otra ciudadanía es posible. Nuevo Itinerario, 16 (2), 191-216. Recuperado de: (agregar dirección web)

\section{Introducción}

Una de las problemáticas que en los últimos años ha logrado ocupar un lugar relevante en el interés investigativo de diversos campos disciplinares es la cuestión referida a los procesos de formación y agencia de la ciudadanía. Las distintas, complejas y cambiantes situaciones políticas que han atravesado numerosos gobiernos democráticos durante las últimas décadas, especialmente en América Latina, la creciente irrupción de diversos grupos sociales en el terreno de disputa por el reconocimiento de determinados derechos básicos, la profundización de las desigualdades en el acceso a un bienestar digno, el creciente formalismo de participación política por parte de los integrantes de la comunidad política como único modo de manifestar su presencia y voz en el terreno de lo público, han generado el diseño de un horizonte teórico de permanente debate acerca de cómo se emplaza la noción de 'ciudadano', cuáles son sus límites discursivos de representatividad y qué expectativas le cabe aún como concepto clave de lo político, en tanto se enuncia como una de las máximas herencias provocadas por la modernidad. En efecto, la filosofía latinoamericana, y en particular el pensamiento dusseliano, ha diseñado una serie de 
De la sociedad civil a la sociedad política: otra ciudadanía es posible.

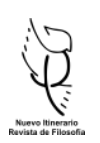

aportes reflexivos destacables para continuar una tratamiento integral y situado de dicho tópico.

En tal contexto, el presente escrito tiene como propósito elaborar una indagación crítica de la categoría 'ciudadanía' a partir del abordaje analítico de dos aspectos claves. Por un lado, el tipo de incidencia epistémica que provoca dicha noción en el contexto de una modernidad colonial vigente que pretende auto-legitimarse como tal. Por otro lado, la dimensión interpelante desde la cual podría operar este concepto en el terreno político, teniendo presente el horizonte teórico habilitado por los debates entre el pensamiento post/descolonial y la Filosofía de la Liberación. Con la finalidad de estructurar tales apuestas teóricas, el trabajo se delineará en cuatro parágrafos. El primero, presentará los principales contenidos que estructuran la hipótesis de la relevancia discursiva y los efectos político-filosóficos que supone el par categorial modernidad-colonialidad. El segundo, explicitará los tres principios políticosnormativos que subyacen a todo orden democrático que pretende legitimar determinadas prácticas de poder -material, formal/democrático y de factibilidadatendiendo a los modos interrelacionales en que cada uno de ellos manifiesta su operatividad. El tercero, recuperará los análisis críticos diseñados por Partha Chatterjee respecto a los tipos de resistencia legítima que ejercen los sujetos subalternizados en el terreno de la sociedad política, en tanto construcción de una ciudadanía que sepa disputar los efectos acerca de cómo se desea ser gobernado. Por último, se analizará de modo crítico el tipo de apropiación de los principios mencionados desde los actuales marcos teóricos de la filosofía latinoamericana en términos de una Política de la Liberación. Además de ello, y a modo de comentarios conclusivos, esta producción esbozará los parámetros discursivos que posibilitarían la comprensión de prácticas ciudadanas cuya dinámica ético-política podría ser interpretada en términos de una resistencia creativa respecto al orden vigente.

Interrogar los condicionamientos ético-epistémicos que definen en el presente a la categoría 'ciudadanía' no sólo será uno de los ejes transversales a las reflexiones que se expondrán sino también constituirá el desafío de advertir nuevas vías de 
interpretación a partir de las cuales dicha noción pueda ser re-apropiada desde su dimensión crítica-liberadora.

\section{Modernidad-Colonialidad: un vínculo categórico problemático y desafiante}

Para presentar los límites dinámicos en los cuales se sitúa el problemático vínculo entre modernidad-colonialidad o también denominado Programa de Investigación de Modernidad/Colonialidad, Arturo Escobar ${ }^{1}$ opta por un interrogante que atravesará la totalidad de sus reflexiones: ¿ por qué sería necesario forjar un nuevo entendimiento de la modernidad? (Escobar, 2003, p. 52). Ante esta cuestión, se exponen dos tendencias teóricas desde las cuales se han ofrecido o se intentan ofrecer una amplia diversidad de respuestas. Cabe destacar que la pregunta nodal planteada se encuentra íntimamente condicionada por las concepciones que configuran al fenómeno de la globalización, y junto con éste, con los elementos desde los cuales se tornaría posible pensar un potencial cambio social.

La primera tendencia corresponde a las perspectivas denominadas por el autor como 'intra-modernas' (Escobar, 2003, p. 54). Siguiendo un interés político, Escobar afirma que se trata de una posición dominante en el terreno de las discusiones entabladas respecto a la modernidad. Teniendo en cuenta los aportes de diversos pensadores europeos (desde el siglo XVIII hasta nuestros tiempos), la modernidad es definida por estas perspectivas de la siguiente manera² (Escobar, 2003, p. 55):

*Desde un punto de vista histórico, encuentra su origen temporal y espacial en el siglo XVII en la Europa del Norte (Francia, Alemania e Inglaterra) alrededor de los fenómenos de la Reforma, la llustración y la Revolución Francesa. La cristalización de estos procesos se sitúa hacia finales del siglo XVIII y se profundiza con la Revolución Industrial.

\footnotetext{
${ }^{1}$ Dos son los argumentos relevantes que orientaron la selección de dicho material teórico: el intento por cumplimentar las expectativas planteadas en el marco del presente trabajo, evitando superarlas como tales, y el hecho de que este escrito representa uno de los "registros de campo" de mayor seriedad y profundización analítica, puesto que su creador es un activo investigador del colectivo. Puesto que la producción de Escobar posee como finalidad presentar las principales búsquedas y desafíos teóricos del colectivo Modernidad-Colonialidad al cual pertenece, su visión particular no opaca el nivel de profundización analítica adoptado para su exposición.

2 El autor también aborda las visiones sociológica y cultural de las perspectivas intra-modernas que no serán tratadas por razones de pertinencia. Para profundizar estos aportes, ver: Escobar, 2003, pp.55-56.
} 
De la sociedad civil a la sociedad política: otra ciudadanía es posible.

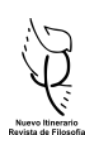

*Filosóficamente, es posible visualizar la modernidad como la emergencia de la noción de Hombre, en tanto fundamento de todo conocimiento y orden en el mundo, distanciado de lo natural y de lo divino.

Pues bien, para la mayoría de los autores considerados por el pensador colombiano, el único orden que puede devenir en global, respecto a su matriz política, es el anteriormente presentado. Es decir, el fenómeno de la globalización sólo puede ser explicado en términos de una radicalización y universalización de la modernidad. El triunfo de lo moderno consiste en haber alcanzado su dimensión global: en su carácter de 'intra-', la construcción de posibles críticas a los efectos negativos del paradigma moderno no podrá superar el horizonte instalado por éste.

Sin embargo, la segunda tendencia introducirá la idea de una modernidad como cuestión abierta y fundamentará la validez/legitimidad de una hipótesis sobre la existencia de auténticas alternativas radicales históricas. En este sentido, se bosquejará de modo sintético las fronteras teóricas, en tanto operaciones que las distinguen de las posturas dominantes sobre la modernidad, más significativas para el colectivo Modernidad/Colonialidad:

*Un importante énfasis en localizar los orígenes de la modernidad a partir de la conquista del continente americano y del control económico del Atlántico después de 1492, destacando el papel fundacional de España y Portugal.

* La persistente atención al colonialismo y al desarrollo del sistema mundo capitalista como elementos constitutivos de la modernidad, particularmente el análisis de la economía y de sus formas de explotación.

* La adopción de una postura planetaria como perspectiva que permita explicar la modernidad como un fenómeno que no puede ser sólo comprendido desde una visión intra-europea.

* La urgencia de explicitar los procesos de dominación de los 'sujetos-otros' que se sitúan fuera del centro europeo como dimensión originaria de la modernidad.

* Una concepción del eurocentrismo como la forma de conocimiento de la modernidad-colonialidad: representación hegemónica del conocimiento que argumenta su propia universalidad. 
Concebir que no sea posible analizar la modernidad sin la colonialidad y destacar la cuestión de la 'diferencia colonial' como lugar epistémico, ético y político privilegiado para efectuar ciertos abordajes críticos, han sido dos pilares que permitieron al colectivo Modernidad-Colonialidad explicitar las potencialidades que guardan las historias locales y proponer así, recorridos teóricos a partir de la praxis política de los grupos subalternos. En efecto, lejos de considerar a Latinoamérica como un objeto de estudio, este programa de investigación propone entenderla como una locación geo-histórica en el que, para protagonizar un locus de enunciación, uno no requiere ser latinoamericano o residente del continente; se trata de una perspectiva que puede ser practicada “(...) en múltiples espacios, con tal de que se constituya desde elaboraciones contrahegemónicas que desafíen el supuesto mismo de Latinoamérica como objeto de estudio constituido, previo a y afuera de los discursos a menudo imperialistas" (Escobar, 2003, p. 69).

\section{La dimensión abismal de la modernidad. El enfoque desafiante de Santos}

En íntima consonancia analítica con lo expuesto por el antropólogo colombiano, Boaventura de Sousa Santos propondrá una tesis radical sobre la cual construirá su propuesta: el pensamiento moderno occidental debe ser comprendido en sus lecturas como un auténtico pensamiento abismal (Santos, 2010, p. 11). Si bien tal supuesto no descarta la posibilidad de que exista alguna otra ejemplificación histórica donde pueda diagnosticarse esta situación, la cuestión de mayor relevancia se emplaza en los modos en que aquellas formas de pensamiento no occidental fueron tratadas por dicho paradigma.

La dimensión abismal que manifiesta la modernidad occidental opera como un dispositivo de producción de distinciones visibles e invisibles (Santos, 2010, p. 12). El grado de visibilidad de algunas será proporcionalmente opuesto al nivel de invisibilidad de otras. Según el planteamiento analítico de Santos, la Sociología de las Ausencias se presenta entonces como una propuesta investigativa que permite desvelar el estatus epistemológico de lo no existente, es decir, las estrategias empleadas a través de las cuales se produce el ocultamiento de determinados objetos en tanto que pierden su 
De la sociedad civil a la sociedad política: otra ciudadanía es posible.

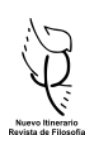

visibilidad-existencia, con el fin de reconocer su presencia simultánea y contemporánea. La monocultura del saber y de su rigor, la monocultura del tiempo lineal, la lógica de la clasificación social, la lógica de la escala dominante y la lógica productivista son las cinco matrices de producción pertenecientes a una misma monocultura racional que operan en pos de asegurar el diseño de lo no existente (Santos, 2006).

En efecto, las diferencias invisibles se diseñan por medio de líneas radicales que establecen una división de dos universos en el plano de lo real: aquel perteneciente a 'este lado de la línea' y aquel correspondiente al 'otro lado de la línea'. La legitimidad de dicha escisión se fundamenta en el ejercicio de invisibilizar el 'otro lado' como espacio inexistente y carente de realidad, en tanto no logre reconocerse a partir de ciertos marcos de comprensión del ser propuesto por 'este lado de la línea'. Es decir, el terreno de lo no existente se emplaza en una política de exclusión promulgada por una determinada concepción de inclusión que indica las fronteras de su reconocimiento. La argumentación principal que valida a este pensamiento abismal consiste entonces en la imposibilidad de advertir la co-presencia de los 'dos lados de la línea'.

En este sentido, el carácter abismal del horizonte moderno occidental se configura como un paradigma socio-político situado en el vínculo conflictivo entre los fenómenos de regulación social y emancipación social. Dicha distinción singulariza el terreno de lo visible donde es posible clarificar ciertos tópicos, en términos de problemas sustantivos y de procedimientos. No obstante, frente a la visibilidad de este espacio existe otra esfera invisible que se torna fundamento del anterior terreno mencionado: la diferenciación entre sociedades metropolitanas y territorios coloniales (Santos, 2010, p. 12).

La importancia de este aporte analítico radica en la potencialidad de advertir las lógicas que operan en estos dos dominios identificados. Así, la dicotomía regulación/emancipación es característica de las sociedades metropolitanas mientras que, en los territorios coloniales, la distinción reinante se legitima en el par categorial apropiación/violencia. En referencia a la distinción de las lógicas que intervienen en cada una de estas órbitas, el pensador portugués sostiene que, en las sociedades 
metropolitanas, la regulación se fundamenta en los principios del Estado, el mercado y la comunidad; la emancipación, en las racionalidades estética-expresiva de las artes y de la literatura, cognitiva-instrumental de la ciencia y tecnología, y moral-práctica de la ética y la ley del Derecho. Por su parte, en los territorios coloniales, la apropiación se legitima a partir de la incorporación, la cooptación y asimilación, mientras que la violencia se emplaza la destrucción física, material, cultural y humana. Resulta interesante destacar que la presencia y tensión de este último par categorial no altera ni contradice la pretendida universalidad de la lógica distintiva en las sociedades metropolitanas.

Sucede entonces que el pensamiento abismal moderno se emplaza en la negación radical de su propia línea divisoria constitutiva, provocando las condiciones necesarias para la validación de una diferencia radical: en 'este lado de la línea', es posible visualizar la distinción entre lo verdadero y lo falso, entre lo legal y lo ilegal; en el 'otro lado de la línea', sólo se advierte un conjunto de experiencias sin sentido y carentes de significatividad, que se invisibilizan tanto en sus agentes como agencias y sin ningún tipo de localización específica. Sin embargo, la órbita ignorada por la división abismal coincidió, originariamente, con el terreno histórico-social enmarcado por la zona colonial. Es decir, el contenido experiencial que quedaba fuera de los criterios de veracidad y legalidad, reconocía en este espacio un lugar propicio para su promoción y dinamicidad.

A partir de mediados del siglo XVI, la determinación de una específica línea global que permita singularizar lo colonial se torna uno de los temas centrales en la discusión política-legal de los Estados europeos concernientes al Nuevo Mundo. En este contexto, tanto el derecho como el conocimiento han sido los principales dispositivos discursivos empleados por la modernidad para legitimarse en su carácter abismal, aunque es posible reconocer una cierta precedencia del primero respecto al segundo. La zona colonial operará así como el andamiaje ocultado que servirá para el diseño de las concepciones modernas de ambas prácticas discursivas mencionadas. El protagonismo otorgado a la labor de los cartógrafos permitió representar a 'lo colonial' como el territorio de lo sin ley. Por ende, las teorías del Contrato Social que 
De la sociedad civil a la sociedad política: otra ciudadanía es posible.

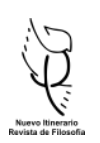

emergieron durante de los siglos XVII y XVIII son de suma relevancia no sólo por lo que explicitan, es decir, la posibilidad que tienen los sujetos metropolitanos de abandonar el estado de naturaleza y conformar una sociedad civil a partir de integrar un determinado contrato, sino que también por aquello que silencian: la producción de una masiva región mundial que permanecerá en los marcos de la idea del estado de naturaleza sin una remota alternativa de lograr conformar una sociedad legítima en términos de civilización. (Santos, 2010, p. 16).

Si el paradigma moderno occidental se enarboló como triunfante a partir de haber logrado el establecimiento de la sociedad civil como etapa superadora del estado de naturaleza, lo que aconteció en términos factuales fue la coexistencia de ambos dominios contrapuestos por una línea abismal en la que el 'ojo hegemónico', situado en la órbita social-civil, dictamina al estado de naturaleza como no existente. En efecto, esta operación significó un tratamiento específico y estratégico de la temporalidad: el presente que actúa al 'otro lado de la línea' se invisibiliza al momento en que es re-significado como un pasado irreversible en 'este lado de la línea'. Ambos lados de la línea existen en una simultaneidad pero se diferencia en su contemporaneidad, es decir, el contacto hegemónico disfraza el pasado para posibilitar la aparición de un singular y hegemónico futuro, garantizando a su vez el requisito del mantenimiento de la universalidad del paradigma (Santos, 2010, p. 17).

La cartografía elaborada por la dimensión abismal de la modernidad se emplazó sobre dos pilares fundamentales: lo legal y lo epistemológico. Tanto lo verdadero como lo falso, lo ilegal y lo legal, son notas que no logran ser válidas al 'otro lado de la línea', puesto que su reino se caracteriza no sólo por la ausencia de ley sino también por la presencia abundante de saberes caracterizados como creencias, magia e idolatría. Las prácticas discursivas de negación empleadas en dicho terreno permitieron distinguir la zona colonial y definirla a partir de una ausencia radical: la humanidad moderna no puede ser concebible sin la producción de una sub-humanidad que, como tal, sufre una exclusión absoluta y no alcanza a obtener los requisitos necesarios para su inclusión social. 


\section{Juan Jesús Puyol}

Los principios implícitos del orden democrático. Hacia una Política de la

\section{Liberación}

Tal como se ha visto, el concepto 'modernidad' ha generado un sinnúmero de debates en los más diversos campos disciplinares. Los intereses investigativos emplazados en la clarificación de los mecanismos que habilitaron a su gestación, al igual que la explicitación de las prácticas discursivas que aseguran su continuidad discontinua singular en el sistema-mundo actual, lograron producir diversos posicionamientos teóricos frente a dicho tópico.

Son varias las corrientes y escuelas filosóficas, históricas, sociológicas y literarias que han trabajado en sus escritos analíticos sobre la relevancia que condensa el pensamiento moderno como horizonte ineludible al momento de emprender un determinado proyecto de investigación, ya sea desde una geopolítica discursiva de asunción del mismo, de superación o de rechazo crítico. Al respecto, cabe ahora fijar la atención en los modos en que el horizonte filosófico dusseliano continúa discurriendo sobre este asunto en torno a las posibilidades factibles de legitimar un determinado orden democrático que habite una modernidad colonial.

Como movimiento complejo y singular dentro del pensamiento latinoamericano, la Filosofía de la Liberación ha emplazado su arquitectónica en una opción ético-política dirigida a reconocer la presencia de una alteridad situada fenómenica e históricamente- como exterioridad a cualquier orden que pretenda totalizarse. Teniendo en cuenta los aportes provenientes del pensamiento levinasiano, entre otras contribuciones conceptuales, la perspectiva latinoamericana liberadora ha logrado argumentar a favor de un 'otro' que revela su distinción cuando se ubica en los márgenes de lo habitual y normado. La exposición de un rostro sufriente e interpelante del sistema excluyente representa la experiencia fenómenica central del mencionado movimiento. En tal contexto, la figura de Enrique Dussel ha sido y es una referencia teórica fundamental para profundizar un tratamiento crítico pertinente de estos supuestos (Solís Bello Ortíz, Zúñiga, Galindo y Gónzalez Melchor, 2011, pp. 399-417).

La concepción dusseliana del 'otro' se fundamenta en su vínculo con la noción de 'exterioridad', recuperada como tal desde la perspectiva propuesta por Emmanuel 
De la sociedad civil a la sociedad política: otra ciudadanía es posible.

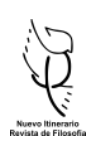

Lévinas y profundizadas por las críticas diseñadas por Karl Marx. Esta metacategoría, considerada a partir de los supuestos de la Filosofía de la Liberación, posibilita las condiciones teóricas para indagar aquella positividad ocultada e ignorada por la visión hegemónica moderna (Dussel, 2011, p. 76). La presencia interpelante de un 'otro' singular y comunitario- habilita la potencialidad para proyectar alternativas colectivas ante aquellas lógicas totalitarias que pretenden hegemonizarse y legitimar sus políticas de exclusión. Si es posible introducir y reconocer una alteridad en el devenir histórico entonces su interpelación exige una serie de respuestas que no sólo revistan el carácter de una propuesta política liberadora, sino que también se validen desde un horizonte ético que supere sus fronteras academicistas.

Sin embargo, y respecto a este tópico, el enfoque dusseliano ha sido centro de diversas críticas. Abonando un debate polémico y atractivo, una de las voces que ha sabido posicionarse en el amplio abanico del pensamiento filosófico latinoamericano ha sido la de Santiago Castro-Gómez. Para el filósofo colombiano, el problema del 'otro' debe ser tratado desde una perspectiva que preste interés al proceso de producción material y simbólica protagonizado por las sociedades occidentales a partir del siglo XVI y no desde un enfoque que suponga, tal como pareciera direccionar la postura de Dussel, la preexistencia de una identidad cultural desde la noción de 'ocultamiento' (Castro-Gómez, 2016, p. 246).

Continuando con el planteo dusseliano, resulta menester destacar que los argumentos esgrimidos sobre la cuestión de la alteridad permiten visualizar una condición -dato antropológico- indispensable para todo intento por indagar la legitimidad de un determinado poder: el ser humano como ser viviente es un ser gregario. Consciente de su vulnerabilidad, éste manifiesta una tendencia a sobrevivir frente a los diversos factores que amenazan su vida. Tal factum es categorizado por Dussel como voluntad de vida. Se trata de aquella potencia que moviliza y sostiene a cualquier sujeto a permanecer en su condición vital, incluso en las peores condiciones imaginadas posibles (Dussel, 2006, p. 23).

A partir de ello, es posible reconocer un ingreso válido a la propuesta política del filósofo argentino. Puesto que la dimensión ética se singulariza por la presencia de 
principios normativos cuya obligación se ejerce de modo diferenciado en los márgenes de cada campo práctico concreto (económico, político, pedagógico, etc.), la normatividad política opera de forma análoga a la obligatoriedad ética, es decir, los principios políticos efectúan una incorporación de los principios éticos para diseñar su propio estatuto. Se trata de reconocer que cada determinación del poder es efecto de una obligación política que actúa como deber, tanto en lo que respecta a las acciones de los actores como así también en el funcionamiento adecuado de las instituciones.

El carácter obligatorio de los principios políticos explicita su finalidad en la afirmación de la voluntad de vida de los agentes, gracias al consenso latente y factible de la comunidad. Desde el enfoque dusseliano, existen al menos tres principios que requieren ser puestos de manifiesto (Dussel, 2006, p. 71): el principio material, referido al aumento y cuidado de la vida de los ciudadanos; el principio formaldemocrático, acerca del cumplimiento efectivo de los procedimientos propios de la legitimidad democrática; y el principio de factibilidad, en tanto que representa las condiciones necesarias para concretizar aquello que sea posible en el terreno político. Vale aclarar que existe una mutua determinación entre dichos principios, sin que esto implique la negación de cierto grado de autonomía -condición condicionante condicionada- (Dussel, 2009, pp. 384-386). A continuación, y de modo breve pero suficiente, se expondrán los elementos teóricos relevantes que constituyen a cada uno de éstos.

*Principio Político Material (Dussel, 2006, p.73). Uno de los principales aspectos analíticos que supo elaborar la filosofía política moderna europea radica en la necesidad de celebrar un pacto que posibilite a la institucionalidad política -estado civil- emplazarse en la potencialidad de la producción, reproducción y aumento de la vida de los integrantes de una específica comunidad. En efecto, señalar lo material como contenido implica, al menos, reconocer la importancia de dos cuestiones centrales: por un lado, el supuesto de que toda acción o institución política debe poseer como referencia última la vida de los ciudadanos y por otro lado, el diseño de las condiciones óptimas para lograr el crecimiento de la vida de cada miembro. Para el filósofo argentino, la materialización de estas máximas pondrá de manifiesto la 
De la sociedad civil a la sociedad política: otra ciudadanía es posible.

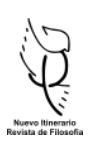

pretensión política de verdad, es decir, el hecho empírico de que se alcance la satisfacción de las necesidades de la corporalidad viviente de los integrantes de la comunidad política demostrará la pretensión política de justicia por parte del agenteacción gubernamental (Dussel, 2009, p. 462).

*Principio Político Democrático (Dussel, 2006, p. 74). En el amplio y complejo espectro de posibles definiciones de lo que se debería entender como democracia, Dussel opta por aquella que la comprende como la institucionalización de las mediaciones que permiten ejecutar acciones e instituciones a través de la legitimidad de un poder delegado. Por ello, y en los marcos de su fundamento, lo democrático configura un principio normativo cuya obligación opera tanto a nivel subjetivo como también en el plano de la intersubjetividad. Tal componente entonces indica que se debe operar de modo que toda decisión política de cada acción, organización o estructuras de una determinada institución (formal o material, de enunciación o aplicación, en su alcance macro o micro) sea fruto de un proceso de acuerdo por consenso en el que se busque garantizar, con el mayor grado de posibilidad existente, la participación de los afectados (Dussel, 2006, p. 78). Dicha simetría de los miembros provocará que la decisión que se tome se imponga como normativa política en el seno de la comunidad. Alejándose de toda ingenuidad, el planteo dusseliano advierte que el factum de la representación no se encuentra exento de una latente corrupción y que, por ende, existe un margen en el que la aplicación de tal principio genera el disenso de ciertas minorías; no obstante, la presencia y voz de éstas permitirán profundizar el progreso cualitativo de la vida, puesto que se intentará remediar los errores y efectos negativos señalados (Dussel, 2009, pp. 417-419).

*Principio Político de la Factibilidad Estratégica (Dussel, 2006, p. 80). Se trata de asumir con la seriedad analítica necesaria el interrogante acerca de la posibilidad por materializar una específica decisión política. De modo análogo a los anteriores principios, la atención está puesta en las posibilidades factibles que se requerirían para operativizar estratégicamente cualquier tipo de acción. Los medios y fines que se enuncien -como contenido- deberán limitarse a las pretensiones del principio material y de la legitimidad determinada por el principio democrático, es decir, se requiere del 
cumplimiento de las condiciones normativas materiales, formales y de las exigencias singulares que diseñan la eficacia política en términos de gestión de la gobernabilidad y de la escasez de recursos. Así, la dimensión factible de la normatividad del poder permitirá pensar las potencialidades de un orden político que no sólo produzca resultados positivos sino también atienda y repare, con la responsabilidad requerida, los efectos negativos no intencionales (Dussel, 2009, p. 471).

\section{La sociedad política: la relevancia de pensar cómo queremos ser gobernados}

Después de haber considerado los lineamientos analíticos de mayor significatividad respecto al vínculo constitutivo entre modernidad-colonialidad como así también los tres principios que, desde la perspectiva dusseliana, diseñan cualquier orden que se defina como democrático, en los siguientes párrafos la atención estará puesta en las reflexiones críticas elaboradas por Partha Chatterjee. Se trata de explicitar cómo ciertas experiencias políticas posibilitan una apropiación novedosa y resistente de la noción moderna de ciudadanía (Chatterjee, 2011).

Al momento de efectuar un abordaje serio de los entrecruzamientos provocados por las categorías de 'nación', 'ciudadanía' y 'modernidad' resulta interesante detectar que la temporalidad que los envuelve se encuentra lejos de definirse por su homogeneidad diferenciada de otros imaginarios pre-modernos. Es decir, lo moderno opera sobre un fondo histórico heterogéneo donde la diferencia cultural -incluso en términos de ancestralidad- no representa la exterioridad a dicho paradigma sino uno de sus más polémicos productos. Oponiéndose a la hipótesis de Anderson acerca de que la política del universalismo pertenece al carácter mismo de la modernidad, el autor sostendrá que el tiempo utópico de capitalismo es el tiempo vacío homogéneo: el tiempo-espacio del horizonte moderno es heterogéneo y desigualmente denso (Chatterjee, 2011, p. 204).

La tensión existente entre el proyecto universal de ciudadanía y el amplio espectro de demandas de reconocimiento y atención específica por parte de numerosas poblaciones étnico-sociales permite advertir que la materialización de este tipo de ciudadanía se torna una forma de vida restringida para unos pocos, mientras 
De la sociedad civil a la sociedad política: otra ciudadanía es posible.

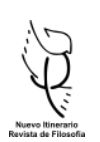

que la mayoría vivencia el fenómeno dentro de los márgenes de la sociedad política. Distanciándose de lo civil, estos grupos asumen su lugar en el entramado de relaciones mediando su agencia en cuanto sujetos de políticas de la gubernamentalidad. La transición acontecida en el siglo XX consistente en el paso de una política democrática basada en la soberanía popular hacia un orden gestionado por la ratio gubernamental investigada por el pensamiento foucaultiano, implicó la oposición entre el ideal universal del nacionalismo cívico -cuya promesa se sustentaba en la igualdad de derechos y en la protección de las libertades individuales- y la exigencia de demandas de ciertos grupos cuyas identidades culturales argumentaban a favor de un tratamiento diferenciado por parte del poder gubernamental (Chatterjee, 2011, p. 205).

Resulta interesante aquí destacar que, en un análisis complementario al expuesto y desde el horizonte del pensamiento latinoamericano, Cullen (2007) elabora una argumentación orientada a la revisión de las condiciones históricas y las correspondencias ético-políticas que condensa la categoría 'ciudadanía'. Las apuestas teóricas del autor argentino remiten a dos aspectos claves. Por un lado, explicitar los vínculos existentes entre los campos de la ética y la política al momento de proponer una determinada subjetividad ciudadana y por el otro, la necesidad de situar el pensamiento con el fin de tensionar, de modo creativo, las aspiraciones universales con las experiencias locales.

En este contexto, y retomando el enfoque del intelectual indio, la sociedad civil puede ser leída como aquella asociación de grupos de élites modernos cuyo dato singular consiste en su aislamiento respecto a la vida popular de mayor amplitud acontecida en las demás comunidades. Así, el mecanismo 'ciudadanía', sea formal o efectiva, habilita la distinción entre quienes gobiernan y los gobernados, siendo necesaria la reflexión de las relaciones que se van suscitando entre sí (Chatterjee, 2011, p. 203).

Siguiendo lo expuesto en los anteriores parágrafos, los ideales de la modernidad colonial supieron emplazarse gracias a la producción del dispositivo 'nación', cuya forma universal se representa a partir de dos dimensiones centrales: la 
idea de un pueblo como lugar de enunciación legítimo para la soberanía del estado moderno y el supuesto de que los individuos son portadores naturales de una determinada cantidad de derechos. Aunque el autor coincidirá con el trazado cronológico de la historia de la ciudadanía occidental elaborado por Marshall -desde los derechos cívicos hasta los derechos políticos en los estados-naciones-, advertirá que este desarrollo ha sido comprimido en aquellos países donde existe una experiencia de dominación europea: las tecnologías de la gubernamentalidad suelen anteceder a la conformación del estado-nación (Chatterjee, 2011, p. 214).

Tanto la libertad como la igualdad posibilitaron el diseño del marco básico en que los derechos fueron definidos por la nación-Estado, a expensas incluso de ciertos conflictos. Siguiendo a E. Balibar, el intelectual indio coincidirá en la relevancia de los conceptos de propiedad y comunidad para afrontar las contradicciones que el binomio libertad-igualdad suele sufrir. La primera noción permite resolver las problemáticas referidas al plano de la relación del individuo con otros; la segunda, logra enfrentar los conflictos en el nivel de la fraternidad como una totalidad. La formación de sujetos que aspiren a convertirse en ciudadanos será la base ética que habilitaría el sostenimiento de la libertad e igualdad en el ámbito político (Chatterjee, 2011, p. 207). En consonancia con ello, es significativo observar que el surgimiento de las democracias de masas en los países avanzados de occidente durante el siglo XX requirió de la diferenciación entre ciudadanos y poblaciones.

Si la categoría de 'ciudadanía' supone una connotación ética de la participación en la soberanía estatal, el concepto de 'población' pretende emplazarse como elemento identificable, descriptible y clasificable, según criterios empíricos, sobre el cual es posible la aplicación de técnicas estadísticas como las encuestas y censos -rasgo del ámbito político, sin un carácter normativo-. Así, se visualiza que el enfoque foucaultiano de la gubernamentalización del Estado será un insumo teórico de gran relevancia para Chatterjee. No sólo para la identificación de aquel régimen cuya legitimidad radica en la mera pretensión de brindar bienestar a la población antes que en la participación de los ciudadanos, sino también en la advertencia de que su razonamiento se funda en una dimensión instrumental de costos y beneficios. Además 
De la sociedad civil a la sociedad política: otra ciudadanía es posible.

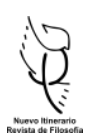

de ello, no se desatenderá a los efectos políticos-gubernamentales que supuso la adopción del "punto de vista social" por parte de la gestión estatal (Chatterjee, 2011, p. 212).

Resulta factible entonces reconocer que la matriz analítica del pensador poscolonial alcanza a vincular dos lineamientos conceptuales que deberían pensarse en sus mutuas conexiones. Por un lado, la relación existente entre el Estado/nación y la sociedad civil cuya validez consistiría en la soberanía del pueblo y en la concesión igualitaria de derechos para los ciudadanos -núcleo duro de la Teoría Política de la Democracia en los últimos siglos-. Por otro lado, la correspondencia de la producción de poblaciones cuyas agencias gubernamentales aspiran a concretizar políticas de bienestar y seguridad. A esto último, el autor denomina sociedad política (Chatterjee, 2011, p. 215).

Tal como es fácilmente registrable durante las últimas décadas, la irrupción de numerosos grupos organizados cuya praxis transgreden las fronteras impuestas de la legalidad en pos de exigir a un determinado orden institucional las condiciones mínimas para vivir y trabajar, genera ciertas dificultades en la gestión gubernamental al momento de responder a sus demandas ${ }^{3}$. Aunque las autoridades políticas de turno no reconozcan su presencia en un plano igualitario respecto a otras asociaciones civiles cuyas prácticas sociales tendrían una mayor legitimidad, es interesante detectar que dichas agencias emplean su visualización en tanto instrumentos convenientes para la administración de la asistencia de grupos de población desfavorecidos y marginales, incluso a costa de evitar mencionarlos bajo la terminología de 'ciudadanía'. Es decir, aceptando la ilegalidad de sus acciones exponen sus diversos reclamos como una cuestión de derechos. Frente a estas demandas por una mayor inclusión en las políticas de bienestar, Chatterjee instalará el siguiente interrogante en el debate político contemporáneo:

¿Qué ocurre entonces si una negociación de este tipo de reclamos sucede en un terreno político en el que, por una parte, los organismos gubernamentales tienen

\footnotetext{
${ }^{3}$ Acerca de esta cuestión, el pensador de la Subalternidad atenderá a los resultados de ciertos estudios etnográficos sobre Bengala Occidental. Para profundizar estos aportes, ver: Chatterjee, 2011, pp. 217218.
} 
una obligación pública de velar por los pobres y los desfavorecidos y, por otra, grupos particulares de población reciben atención de esas agencias de acuerdo con los cálculos de conveniencia política? (Chatterjee, 2011, p. 218). ${ }^{4}$

Este cuestionamiento permite deducir que la sociedad civil, cuya representación poblacional -según el autor- es limitada y restringida a ciertos ciudadanos, implica en determinados países no sólo el éxito del modelo constitucional estatal sino también la plenitud del proyecto gubernamental moderno. En tal sentido, los diversos cuerpos de gobierno necesitan descender al ámbito de la sociedad política para asumir una doble exigencia irrenunciable: la renovación de su legitimidad en cuanto representa la gestión del bienestar y el deber de escuchar-responder a la configuración actual de las demandas que se movilizan políticamente. Las nociones de 'refugiados', 'colonos', 'jornaleros', los 'sin tierra', se configuran como categorías demográficas de la gubernamentalidad que habilitan a estos actores a definir sus identidades en los marcos de la sociedad política, donde sus reclamos tienen el potencial de provocar ciertas distorsiones en los vínculos con el poder estatal. Así, se diferencian de la rigidez que supone la ley establecida y su procedimiento administrativo. (Chatterjee, 2011, p. 221)

El campo heterogéneo, las múltiples estrategias y la variedad de grupos sobre los cuales debe operar la ratio gubernamental señalan la imposibilidad de un ejercicio uniforme e igualitario de los derechos de la ciudadanía. En efecto, la sociedad política indica aquel terreno donde los individuos excluidos de los márgenes del ámbito civilformal construyen una relación activa con los procedimientos de la gubernamentalidad, cuyo resultado serán expuestos en determinados éxitos temporales y contextuales según las demandas que se plantean ${ }^{5}$. Aunque también se encuentre latente la manifestación de la dimensión violenta y miserable de la vida

\footnotetext{
${ }^{4}$ Para el autor, la frecuencia del uso instrumental que realizan estos grupos respecto a la posibilidad de ejercer un cierto impacto al momento de participar en las elecciones, señala los indicios a través de los cuales se observarían los modos en que la ciudadanía se superpone con los intereses de la ratio gubernamental.

${ }^{5}$ Desde un posicionamiento diferente pero complementario a estos argumentos, Dussel entenderá que lo civil y lo político se diferencian por el grado de sistematicidad institucional que manifiestan en el campo político. Mientras que la sociedad civil señala un Estado ampliado -en sentido gramsciano-, la sociedad política indica su sentido restringido. Para profundizar estos aspectos, ver: Dussel, 2009, pp. 244-273.
} 
De la sociedad civil a la sociedad política: otra ciudadanía es posible.

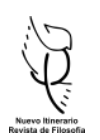

popular -crimen, delincuencia, etc.- es evidente que la igualdad y libertad enarboladas por el proyecto democrático no pueden quedar apresadas en los límites de la sociedad civil. Si el principio aristotélico que sostiene nuestras prácticas gubernamentales radica en la imposibilidad de que todos gobiernen, la soberanía popular comienza a discurrir los senderos donde sea posible el diseño de nuevas formas que permitan, al menos, definir cómo ser gobernados: la democracia ya no será definida en términos del gobierno de-por-para el pueblo sino de una auténtica política de los gobernados (Chatterjee, 2011, p. 203).

\section{Voz y presencia de las víctimas: los tres principios políticos críticos de} Liberación

El diagnóstico crítico elaborado por el pensador Partha Chatterjee a partir del señalamiento de los márgenes ético-discursivos del ámbito civil y de la potencialidad que surge de evidenciar una subjetividad participante de la sociedad política al momento de diseñar estrategias que definan el cómo ser gobernados, obliga una revisión de los principios del orden democrático explicitados con anterioridad. Aunque sea factible reconocer que tales normas constituyen al poder desde su dimensión interna, resulta indudable que no existe sistema político que sea perfecto. La exclusión, en la participación de las decisiones, de aquellos que sufren tales efectos negativos (en su corporalidad viviente) demuestra la ineficacia del sistema y su ilegitimidad. Pues bien, el horizonte teórico de la Filosofía Política de la Liberación permitirá a Enrique Dussel proponer tres principios críticos que intentarán asumir los diferentes retos políticos contemporáneos: el principio material liberador, el principio crítico democrático y el principio político crítico de factibilidad (Dussel, 2006, p. 100). Además de contener determinadas afirmaciones irrenunciables, estos principios se encuentran configurados por una fuerte negatividad que enfrenta dos cuestiones claves: la positividad injusta del sistema y la legitimidad-eficiencia que pretende defender. La ineficiencia del sistema dominador es el contexto que catapulta el escepticismo del crítico respecto a dicho orden. En las siguientes líneas se presentará brevemente los contenidos principales de cada uno de ellos. 
*Principio Material Liberador (Dussel, 2006, p. 102). El contenido último de toda acción o institución política radica en el aumento de la calidad de vida de los integrantes de una determinada comunidad. Si el ejercicio político puede comprenderse en términos de un consenso factible que legitima la voluntad de vivir, las víctimas de tal orden -aquellas que sufren los efectos indeseados de dicho consenso- señalan el contenido patológico del sistema. El momento creativo de la política como praxis de liberación postula la transformación de las instituciones en pos de asegurar la producción y reproducción de la vida de los excluidos-víctimas ${ }^{6}$ (Dussel, 2009, p. 462).

*Principio Crítico Democrático (Dussel, 2006, p. 105). Las acciones e instituciones que son legitimadas por el principio democrático normativo no logran garantizar un orden político que se caracterice por el cumplimiento efectivo y universal de sus aspiraciones. Como fuera advertido en el parágrafo anterior, el consenso crítico alcanzado por las víctimas de tal sistema provoca un disenso con el antiguo acuerdo vigente. En efecto, este principio promueve un compromiso donde se garantiza la participación real, y en condiciones de simetría, de los afectados por las decisiones institucionales que acontecieron en el pasado. No se trata de aspirar a la inclusión en el antiguo sistema -introducción del 'Otro' en 'lo Mismo' - sino en una transformación que posibilite un nuevo momento institucional que reconozca la presencia y voz de las víctimas del sistema político vigente (Dussel, 2009, p. 405).

*Principio Político Crítico de Factibilidad (Dussel, 2006, p. 106). A diferencia de la praxis gubernamental de un orden vigente, aquellos sectores que aspiran a la transformación de las instituciones se encuentran con mayores dificultades estratégicas. Por ello, dicho principio postula la necesidad de obrar lo máximo posible adoptando como condición de posibilidad, en la tarea transformadora del sistema, la liberación de las víctimas de tal orden. Los encargados de ejercer el poder político delgado no están exentos de cometer errores pero sí se les debe exigir, de modo

\footnotetext{
${ }^{6} \mathrm{El}$ enfoque dusseliano propone el tratamiento analítico de las dimensiones ecológica, económica y cultural como sub-esferas que constituyen a este principio. Para profundizar estos aportes, ver: Dussel, 2009, pp. 209-238.
} 
De la sociedad civil a la sociedad política: otra ciudadanía es posible.

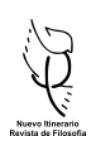

normativo, el cumplimiento honesto de su vocación, garantizando la presencia de los elementos constitutivos de un acto justo (Dussel, 2009, p. 480).

En suma, la co-dependencia de estos tres principios críticos diseñan los marcos requeridos para la materialización de una auténtica pretensión de justicia política: iluminando las acciones liberadoras y de transformación, posibilitan la evidencia de los errores cometidos y elaboran los criterios exigidos para su corrección (Dussel, 2009, pp. 516-520).

\section{Comentarios finales: hacia una ciudadanía transmoderna}

La apuesta por elaborar un tratamiento crítico de la categoría 'ciudadanía', a partir de los argumentos principales diseñados por aquel horizonte teórico habilitado por el pensamiento post/descolonial y la Filosofía de la Liberación, condensa una serie de expectativas analíticas que han superado los límites del presente escrito. Sin embargo, el recorrido discursivo propuesto ha permitido destacar una serie de componentes teóricos indispensables para consolidar una tarea investigativa situada acerca de dicho tópico.

La pregunta planteada por el antropólogo colombiano acerca de por qué resulta necesario forjar un nuevo entendimiento de la modernidad, además de haber explicitado las principales tendencias que han logrado ofrecer una respuesta válida, evidencia la existencia de prácticas discursivas que fundamentaron un determinado relato del horizonte moderno. Se trata de un conjunto de supuestos que, siendo hegemonizados, serán incuestionables para la mayoría de los saberes disciplinares y para los debates protagonizados en los principales centros académicos. Destacando la relevancia epistémica que guarda la noción 'diferencia colonial', y gracias a los aportes de Santos, se visualizó uno de los efectos que supone profundizar la relación categorial modernidad-colonialidad. En términos de un pensamiento abismal, el horizonte moderno se comporta como un auténtico dispositivo de producción de distinciones visibles e invisibles y que distingue la presencia, simultánea pero no contemporánea, de sociedades metropolitanas -a 'este lado de la línea'- y de territorios coloniales -al 'otro lado de la línea'-. 
El proyecto normativo/institucional elaborado por la crítica dusseliana, manifestado en los principios implícitos de todo orden democrático y en aquellos requeridos para un ejercicio de política liberadora, remite a visualizar la potencia que supone la irrupción de una alteridad víctima para la creación de una auténtica comunidad plural. Resulta evidente que, dada la dimensión abismal de la modernidad colonial, las denuncias y reclamos provenientes de aquel 'otro' del sistema no encontrarán la deseada validez ético-política en el mismo terreno estatal que lo excluye. Tal como fuese advertido por Chatterjee, el entramado de sentido de la praxis de dichos grupos marginados reconoce que el fundamento de su subsistencia en la totalidad, de resistir y sobrevivir en la represión, de su estar-siendo en nefastas condiciones, es un proyecto de liberación utópico: como aquello que no tiene lugar en la totalidad (ouk topos) y que se eyecta hacia un bien y un futuro social alternativo (Dussel, 1983, p. 127). Es por ello que la esperanza que alimenta estas experiencias de defender y luchar por la vida se funda en un ámbito absolutamente irreprimible, jamás incluido y siempre exterior. El interrogante acerca de cómo ser gobernados y la necesaria resistencia que ofrecen los sujetos subalternizados al interior de una sociedad política actualizan sus accesos posibles de continuo análisis crítico.

Para finalizar, se destacarán dos aportes de Dussel que permitirán dilucidar algunos derroteros investigativos pendientes sobre la temática abordada. Se trata de un conjunto de reflexiones que ofrecerán insumos conceptuales para continuar un tratamiento crítico del siguiente doble cuestionamiento proyectivo: ¿Qué actitud éticapolítica sería necesaria para forjar otra ciudadanía y qué horizonte de pensamiento se requiere para concretizar el protagonismo ciudadano en nuestras modernidades coloniales?

Para los márgenes diseñados por el filósofo argentino en su Política de la Liberación, y respondiendo al primer interrogante, se debería transitar un camino que atraviese el límite de la intolerancia, hacia la tolerancia, finalizando en la solidaridad (Dussel, 2007, p. 293). Si la intolerancia es aquella opción que consiste en permanecer intransigente -a través de la violencia- a posibles oponentes y la tolerancia representa una cierta pasividad y, hasta cierto punto, un grado de indiferencia hacia al 'otro', 
De la sociedad civil a la sociedad política: otra ciudadanía es posible.

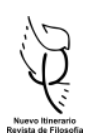

entonces habría un estadio ético-político que los superaría. Existe una posición que manifiesta una mayor afirmación, un radical compromiso por asumir la responsabilidad por el 'otro' como 'otro', una constante colaboración con la víctima por defender sus derechos negados y marginados. Es decir, el 'otro' no es ya solamente tolerado, sino que, afirmando su exterioridad, es respetado en su alteridad, en su ser distinto, desde una perspectiva solidaria. De este modo, se definirá a la solidaridad como “(...) una pulsión de alteridad, un deseo metafísico (E. Lévinas) por el otro que se encuentra en la exterioridad del sistema donde reina la tolerancia y la intolerancia" (Dussel, 2007, p. 298).

En referencia al segundo interrogante, el pensamiento dusseliano ha elaborado un proyecto teórico que pretende operar como horizonte válido para una posible ciudadanía descolonial. Se trata de la transmodernidad. Como concepto propositivo y crítico, lo transmoderno configura un proceso que se origina desde aquel 'otro lugar' que ha sobrevivido a los avatares de la modernidad y que concentra el potencial necesario para el diseño de una pluralidad cultural alternativa a los relatos posmodernos globalizadores. Por ello, la transmodernidad resulta ser una categoría que opera en dos dimensiones simultáneas y vinculadas entre sí: como concepto de análisis crítico, promueve la humanización/liberación humana $y$, en tanto noción normativa, explicita una orientación posible hacia la superación del horizonte moderno, respecto de sus lógicas anti-humanizadoras (Acosta, 2015, p. 23). Su carácter utópico tensiona no sólo la elaboración de una meta empírica a ser históricamente realizable en cuanto posible sino también el requisito de una función crítico-reguladora destinada a legitimar las transformaciones del presente con sentido de futuro alternativo, aún a costa de que su concretización no sea plena y total. En efecto, se señala la irrupción de aquella novedad radical proveniente de la exterioridad alterativa de lo siempre distinto, es decir, aquellas culturas universales en desarrollo que asumen los desafíos de la modernidad y del proyecto posmoderno pero que deciden diseñar sus respuestas desde otros locus/lugares, imposibles de ser pensadas tan sólo por el reductivo enfoque moderno (Dussel, 2016, p. 283). 
En suma, si la solidaridad se emplaza como aquella actitud ético-política necesaria para postular otros sentidos que singularicen al significante 'ciudadanía' y el proyecto transmoderno se sitúa como un horizonte válido para el ejercicio de prácticas ciudadanas descoloniales, entonces se torna viable ampliar la inquietud del pensador indio aquí citado: un tránsito analítico que atravesaría desde cómo deseamos ser gobernados a cómo deberíamos habitar, desde una resistencia creativa y no sólo en el campo político, nuestras modernidades coloniales. Pues bien, los caminos investigativos pendientes por desandar se evidencian y este escrito sólo representa un registro de los trayectos ya alcanzados. En palabras finales de Carlos Cullen:

La ciudadanía es una categoría densa, porque es histórica, porque es compleja, y sobre todo, porque no puede reducirse ni a un concepto, ni a un personaje, ni a una fantasía, ni a un derecho, ni a una pertenencia, ni a una resistencia. Se trata de resignificar estos tópicos, ciertamente presentes en la densidad de la ciudadanía, desde lo que la define simpliciter, la vulnerabilidad, que nos convierte en responsables, y como diría Lévinas, rehenes de los otros (Cullen, 2007, p.

\section{Bibliografía}

Acosta, Y. (2015) Desde una Transmodernidad Liberadora. Revista de Filosofía en el Perú. Pensamientos e ideas, 7, pp. 21-33. Recuperado de: http://refperu.com/2\%20Yamandu\%2021-33.pdf. Fecha de acceso: 12/08/20

Castro-Gómez, S. (2016) Ciencias sociales, violencia epistémica y el problema la invención del otro. En E. Lander (Comp.), La colonialidad del saber: eurocentrismo y ciencias sociales. Perspectivas latinoamericanas (pp. 163-179) [2000]. Buenos Aires: Fundación CICCUS.

Chatterjee, P. (2011) Dheli Lecture. La política de los gobernados. Revista Colombiana de Antropología, 47, 199-231. Recuperado de: http://www.redalyc.org/articulo.oa?id=105021311009. Fecha deacceso: $10 / 08 / 20$

Cullen, C. (2007) Resistir con inteligencia. México D.F.: Pueblo Nuevo. 
De la sociedad civil a la sociedad política: otra ciudadanía es posible.

Dussel, E. (1983) Praxis Latinoamericana y Filosofia de la Liberación. Bogotá: Nueva América. Recuperado de: $\mathrm{http} / / /$ www.ceapedi.com.ar/imagenes/biblioteca/libros/96.pdf. Fecha de acceso:07/08/20

Dussel, E. (2006) 20 Tesis de Política. México D.F.: Siglo XXI y Centro de Cooperación Regional para la Educación de Adultos en América Latina y el Caribe (CREFAL).

Dussel, E. (2007) Materiales para una Política de la Liberación. México D.F.: Plaza y Valdés Editores. Recuperado de: http://enriquedussel.com/txt/Materiales\%20(a).pdf. Fecha de acceso:10/08/20

Dussel, E. (2009) Política de la Liberación. Arquitectónica. Vol. II. Madrid: Trotta.

Dussel, E. (2011) Filosofía de la Liberación. [1977]. México D.F.: Fondo de Cultura Económica.

Dussel, E. (2016) Filosofías del Sur. Descolonización y transmodernidad. [2015]. México: Ediciones Akal.

Escobar, A. (2003) Mundos y conocimientos de otros modos. El programa de investigación modernidad/colonialidad latinoamericano. Tabula Rasa, 1, 51-86. Recuperado de: http://www.unc.edu/ aescobar/text/esp/escobar-tabula-rasa.pdf. Fecha de acceso: 08/08/20

Santos, B. (2006) Conocer desde el Sur. Para una cultura política emancipatoria. Lima: Fondo Editorial de la Facultad de Ciencias Sociales. Recuperado de: http://www.boaventuradesousasantos.pt/pages/pt/livros.php Fecha de acceso: $11 / 08 / 20$

Santos, B. (2010) Para descolonizar Occidente: más allá del pensamiento abismal. Buenos Aires: Consejo Latinoamericano de Ciencia Sociales (CLACSO) y Prometeo Libros.

Solís Bello Ortíz, N., Zúñiga, J., Galindo, M., Gónzalez Melchor, M. (2011) La Filosofía de la Liberación. En: E. Dussel, E. Mendieta y C. Bohórquez (Comps.), El pensamiento filosófico latinoamericano, del Caribe y "latino" (1300-2000): historia, corrientes, temas y filósofos (pp. 399-417). México: Siglo XXI. 